\title{
Rapid identification of micro-organisms from urinary tract infections by $\beta$-glucuronidase, phenylalanine deaminase, cytochrome oxidase and indole tests on isolation media
}

\author{
G. GIAMMANCO and SARINA PIGNATO \\ Istituto d'Igiene e Medicina Preventiva, Università di Catania, Via Biblioteca 4, 95124 Catania, Italy
}

\begin{abstract}
Summary. Two commercially available media recommended for the isolation and rapid identification of Escherichia coli from urinary tract infections were supplemented with Lphenylalanine and L-tryptophan. The non-selective medium proved suitable for the direct detection of lactose fermentation, $\beta$-glucuronidase and phenylalanine deaminase activities, indole production and the oxidase test. It was highly efficient in making a presumptive identification at species level of the most common gram-negative urinary pathogens, E. coli, Proteus mirabilis and Pseudomonas aeruginosa, that account for $c .85 \%$ of all urinary isolates. Among the gram-positive isolates, most colonies were non-fluorescent and could be separated into staphylococci and enterococci on the basis of the catalase test. Fluorescent colonies were found to be Staphylococcus haemolyticus isolates, $61 \%$ of which were fluorescent. The selective medium proved suitable for the same biochemical tests, with the exception of indole, which was not visible against the red colour of the medium. Therefore, the differentiation of P. mirabilis from other Proteus-Providencia species was impossible on this medium.
\end{abstract}

\section{Introduction}

Urinary tract infections (UTI) occur commonly both in outpatients and inpatients. Escherichia coli and Proteus mirabilis are the bacteria most commonly isolated from infected urine specimens, followed by other gram-negative and gram-positive microorganisms. The traditional selective and non-selective plating media for isolating and enumerating urinary tract pathogens contain lactose, but lactose fermentation is of limited value for the full identification of the isolates.

For many years certain enzymic activities have been used extensively for the differentiation of Enterobacteriaceae. ${ }^{1-4}$ In particular, complex media for the rapid identification of pathogenic enterobacteria by $\beta$ galactosidase and phenylalanine deaminase tests ${ }^{5}$ and for direct identification of $E$. coli in clinical specimens $^{6-9}$ by chromogenic or fluorogenic substrates for $\beta$-glucuronidase detection have been proposed.

In the present study, two commercially available solid media recommended for $\beta$-glucuronidase detection were supplemented with amino acids for phenylalanine deaminase and indole tests. The media were assayed with collection strains and clinical specimens for their usefulness in the rapid identification of urinary tract pathogens.

\section{Materials and methods}

\section{Bacterial strains}

The bacterial strains belonging to various enterobacterial and other gram-negative species were obtained from the collections of the Unité des Entérobactéries, Institut Pasteur, Paris (France) and of the Istituto d'Igiene e Medicina Preventiva of the University of Catania (Italy).

\section{Urine specimens}

Urine for culture was obtained as midstream or catheter specimens from inpatients and outpatients with symptoms of UTI. The specimens were diluted 1 in 100 and 1 in 10000 and $0.1 \mathrm{ml}$ of each dilution was inoculated on plates of the isolation media, then incubated at $37^{\circ} \mathrm{C}$ for $18-24 \mathrm{~h}$.

\section{Isolation media}

The isolation media were Fluorocult-Brolacin Agar (a non-selective medium similar to CLED) (FBA; 
Table I. Biochemical and enzymatic reactions observed on modified Fluorocult-Brolacin agar and MacConkey agar MUG with 219 collection strains of gram-negative bacteria

\begin{tabular}{|c|c|c|c|c|c|c|c|c|c|c|c|}
\hline \multirow{2}{*}{ Species } & \multirow{2}{*}{$\begin{array}{l}\text { Number } \\
\text { of strains }\end{array}$} & \multicolumn{2}{|c|}{ Lac } & \multicolumn{2}{|c|}{ MUG } & \multicolumn{2}{|c|}{ PAD } & \multicolumn{2}{|c|}{ Ind } & \multicolumn{2}{|c|}{ Oxid } \\
\hline & & + & - & + & - & + & - & + & - & + & - \\
\hline E. coli & 57 & 57 & 0 & 53 & 4 & 0 & 57 & 56 & 1 & 0 & 57 \\
\hline$K$. pneumoniae & 20 & 20 & 0 & 0 & 20 & 0 & 20 & 0 & 20 & 0 & 20 \\
\hline K. oxytoca & 22 & 22 & 0 & 0 . & 22 & 0 & 22 & 22 & 0 & 0 & 22 \\
\hline C. freundii & 10 & 10 & 0 & 0 & 10 & 0 & 10 & 0 & 10 & 0 & 10 \\
\hline Ent. agglomerans & 12 & 4 & 8 & 0 & 12 & 0 & 12 & 0 & 12 & 0 & 12 \\
\hline Ent. cloacae & 10 & 8 & 2 & 0 & 10 & 0 & 10 & 0 & 10 & 0 & 10 \\
\hline Levinea malonatica & 4 & 0 & 4 & 0 & 4 & 0 & 4 & 4 & 0 & 0 & 4 \\
\hline L. amalonatica & 4 & 0 & 4 & 0 & 4 & 0 & 4 & 4 & 0 & 0 & 4 \\
\hline P. vulgaris & 12 & 0 & 12 & 0 & 12 & 12 & 0 & 12 & 0 & 0 & 12 \\
\hline P. mirabilis & 12 & 0 & 12 & 0 & 12 & 12 & 0 & 0 & 12 & 0 & 12 \\
\hline Providencia alcalifaciens & 7 & 0 & 7 & 0 & 7 & 7 & 0 & 7 & 0 & 0 & 7 \\
\hline Pr. stuartii & 12 & 0 & 12 & 0 & 12 & 12 & 0 & 12 & 0 & 0 & 12 \\
\hline Pr. rettgeri & 12 & 0 & 12 & 0 & 12 & 12 & 0 & 12 & 0 & 0 & 12 \\
\hline Morganella morganii & 12 & 0 & 12 & 0 & 12 & 12 & 0 & 12 & 0 & 0 & 12 \\
\hline Acinetobacter calcoaceticus & 3 & 0 & 3 & 0 & 3 & 0 & 3 & 3 & 0 & 0 & 3 \\
\hline Ps. aeruginosa & 10 & 0 & 10 & $10^{*}$ & 0 & 0 & 10 & 0 & 10 & 10 & 0 \\
\hline
\end{tabular}

Lac, lactose fermentation; MUG, methylumbelliferyl- $\beta$-D-glucuronide hydrolysis by $\beta$-glucuronidase (UV light fluorescence); PAD, phenylalanine deaminase; Ind, indole production on modified Fluorocult-Brolacin agar; Oxid, cytochrome oxidase test.

* Green fluorescence for fluorescein under UV light.

Merck, Darmstadt, Germany) and MacConkey Agar MUG (Biolife Italiana, Milano, Italy), both containing methylumbelliferyl- $\beta$-D-glucuronide (MUG) for the detection of $\beta$-glucuronidase. They were modified for the detection of phenylalanine deaminase and indole production as follows: FBA was supplemented with L-phenylalanine $0.2 \%$ and L-tryptophan $0.3 \%$, and MacConkey Agar MUG was supplemented with L-phenylalanine $0 \cdot 2 \%$. In both media, lactose fermentation was revealed by the colour change of the $\mathrm{pH}$ indicators. $\beta$-Glucuronidase activity was detected by examining the plates at a wavelength of $366 \mathrm{~nm}$ for blue fluorescence due to the methylumbelliferone released by hydrolysis of MUG. Green fluorescence due to pyoverdin produced by Pseudomonas spp. was also recorded. The production of phenylpyruvic acid by phenylalanine deaminase was revealed by dropping one to two drops of a ferric chloride $10 \%$ solution on the colonies, whereupon positive colonies rapidly developed a green colour on the non-selective medium and a dark green colour turning to black on the selective one. Cytochrome oxidase was tested with oxidase sticks (Unipath). The production of indole was detected on the non-selective medium by dropping one or two drops of Kovac's reagent on the colonies. The selective medium proved unsuitable for indole detection, even if supplemented with L-tryptophan, because the reaction was not visible against the red colour of the medium.

\section{Identification of isolates}

The presumptive identification of urinary isolates was made on the basis of the macroscopic characteristics of colonies, the microscopic observation of gram-stained slides, the biochemical reactions on the two isolation media (lactose fermentation, $\beta$-glucuronidase, phenylalanine deaminase, oxidase and indole tests). The final identification of isolates was made with commercially available biochemical systems: API20 E, API20 NE, API20 STREP or API STAPH (BioMérieux, Marcy-L'Etoile, France).

\section{Results}

In table I the results observed on the two modified media with 219 collection strains belonging to the gram-negative species most frequently isolated from urine specimens are reported. The biochemical reactions obtained in both media were in agreement with those reported for the corresponding species. ${ }^{10} \mathrm{Be}-$ cause of their fluorescent pigment, Ps. aeruginosa strains showed green fluorescence under UV light, that was easily distinguishable from the blue fluorescence of $E$. coli strains. No fluorescence was seen with the other nine Pseudomonas isolates.

The presence of gram-negative bacteria in significant numbers $\left(>10^{5} \mathrm{cfu} / \mathrm{ml}\right)$ was observed in 158 urine specimens on both media. The bacterial counts on the selective and non-selective medium did not differ significantly. Of the 158 isolates, $128(81 \%)$ were correctly identified to species level directly on modified FBA (102 E. coli, 18 P. mirabilis, five Klebsiella oxytoca and three $P$ s. aeruginosa), four isolates were identified to genus level as Proteus-Providencia spp. (two P. vulgaris, one Pr. stuartii and one Morganella morganii), 11 were identified as 'coliform bacteria' (five $K$. pneumoniae, one Enterobacter cloacae, one Ent. agglomerans, two Citrobacter freundii, one Serratia marcescens and one $S$. liquefaciens), and nine isolates (eight Ps. putida, one Ps. maltophilia) were not 
Table II. Presumptive and final identification of 158 gram-negative bacteria isolated from urines on modified media

\begin{tabular}{|c|c|c|c|}
\hline $\begin{array}{l}\text { Presumptive } \\
\text { identification }\end{array}$ & $\begin{array}{l}\text { Number } \\
\text { of isolates }\end{array}$ & $\begin{array}{c}\text { Final } \\
\text { identification }\end{array}$ & $\begin{array}{l}\text { Number } \\
\text { of isolates }\end{array}$ \\
\hline E. coli & 102 & E. coli & 102 \\
\hline K. oxytoca* & $11 \dagger$ & $\begin{array}{l}\text { K. oxytoca } \\
\text { E. coli }\end{array}$ & $\begin{array}{l}5 \\
6\end{array}$ \\
\hline Coliform bacteria & 11 & $\begin{array}{l}\text { K. pneumoniae } \\
\text { Ent. cloacae } \\
\text { Ent. agglomerans } \\
\text { C. freundii } \\
\text { S. marcescens } \\
\text { S. liquefaciens }\end{array}$ & $\begin{array}{l}5 \\
1 \\
1 \\
2 \\
1 \\
1\end{array}$ \\
\hline P. mirabilis* & $18 \ddagger$ & P. mirabilis & 18 \\
\hline Proteus-Providencia spp. & 4 & $\begin{array}{l}\text { P. vulgaris } \\
\text { Pr. stuartii } \\
\text { M. morganii }\end{array}$ & $\begin{array}{l}2 \\
1 \\
1\end{array}$ \\
\hline $\begin{array}{l}\text { Ps. aeruginosa } \\
\text { Oxidase-positive bacteria } \\
\text { Other gram-negative bacteria }\end{array}$ & $\begin{array}{l}3 \S \\
8 \\
1\end{array}$ & $\begin{array}{l}\text { Ps. aeruginosa } \\
\text { Ps. putida } \\
\text { Ps. maltophilia }\end{array}$ & $\begin{array}{l}3 \S \\
8 \\
1\end{array}$ \\
\hline
\end{tabular}

* On modified Fluorocult-Brolacin agar.

† Identified as "coliform bacteria" on MacConkey agar MUG.

‡ Identified as "Proteus-Providencia spp." on MacConkey Agar MUG.

$\S$ Green fluorescent colonies when exposed to UV light.

identified (table II). Misidentification occurred with six $E$. coli isolates, whose presumptive identification was $K$. oxytoca because they were MUG negative and indole positive. On the other hand, nine indolenegative isolates were identified correctly as $E$. coli by their MUG positivity.

One hundred and two isolates were identified correctly as $E$. coli on the modified MacConkey Agar MUG. On this medium, the differentiation of $K$. oxytoca from 'coliform bacteria' and $P$. mirabilis from other isolates presumptively identified as ProteusProvidencia spp. was not possible without the indole test.

Specificity and sensitivity of presumptive identification of $E$. coli on both media were, respectively, $100 \%$ and $94 \%$. Modified FBA showed $100 \%$ sensitivity and specificity in the identification of $P$. mirabilis isolates. On the basis of the results obtained with the collection strains and the wild isolates, reaction patterns were formulated (table III) for rapid identification of the majority of gram-negative bacteria causing UTI. With Ps. aeruginosa and occasionally other Pseudomonas spp. green fluorescence was an additional identification factor. ${ }^{11}$

Gram-positive micro-organisms were isolated only on modified FBA. They were separated into staphylococci and enterococci on the basis of the catalase test and identified with API STAPH and API20 STREP, respectively. Gram-positive cocci were shown in significant numbers $\left(\geqslant 10^{5} \mathrm{cfu} / \mathrm{ml}\right)$ in 26 urine specimens: Enterococcus faecalis, 20; Staphylococcus epidermidis, four; Staph. aureus, one; Staph. haemolyticus, one. Entero. faecalis and staphylococci belonging to different species were isolated in non-significant numbers $\left(10^{3}-10^{4} \mathrm{cfu} / \mathrm{ml}\right)$ from a further 45 specimens, 13 of which contained two species (Entero. faecalis and a staphylococcus or two different staphylococci). Blue
Table III. Reaction patterns of gram-negative isolates from UTI on modified non-selective medium

\begin{tabular}{|c|c|c|c|c|c|}
\hline \multicolumn{5}{|c|}{ Reaction patterns* } & \multirow{2}{*}{ Identification } \\
\hline Lac & MUG & PAD & Ind & Oxid & \\
\hline+ & + & - & \pm & - & E. coli \\
\hline+ & - & - & $\overline{+}$ & - & K. oxytoca, E. coli \\
\hline+ & - & - & - & - & Other coliform bacteria \\
\hline- & - & + & - & - & P. mirabilis \\
\hline- & - & + & + & - & Proteus-Providencia spp. \\
\hline- & $+(f)$ & - & - & + & $\begin{array}{l}\text { Ps. aeruginosa or other } \\
\text { fluorescent Pseudomonas spp }\end{array}$ \\
\hline- & - & - & - & \pm & $\begin{array}{l}\text { Pseudomonas or other } \\
\text { gram-negative bacteria }\end{array}$ \\
\hline
\end{tabular}

*See table I for explanation of abbreviations.

(f) Green fluorescence for fluorescein under UV light.

Table IV. Results of the identification of $11 \mathrm{UV}$ fluorescent and 73 non-fluorescent isolates of gram-positive cocci from modified non-selective medium

\begin{tabular}{|c|c|c|c|}
\hline $\begin{array}{l}\text { UV fluorescent } \\
\text { catalase-positive }\end{array}$ & 11 & Staph. haemolyticus & 11 \\
\hline \multirow{8}{*}{$\begin{array}{l}\text { UV non-fluorescent } \\
\text { catalase-positive }\end{array}$} & 31 & Staph. aureus & 1 \\
\hline & & Staph. haemolyticus & 7 \\
\hline & & Staph. epidermidis & 7 \\
\hline & & Staph. simulans & 5 \\
\hline & & Staph. hominis & 3 \\
\hline & & Staph. sciuri & 2 \\
\hline & & Staph. warneri & 1 \\
\hline & & Not identified & 5 \\
\hline $\begin{array}{l}\text { UV non-fluorescent } \\
\text { catalase-negative }\end{array}$ & 42 & Entero. faecalis & 42 \\
\hline
\end{tabular}

fluorescence under UV light was observed with only 11 of 18 Staph. haemolyticus isolates (table IV). The fluorescent Staph. haemolyticus colonies were easily distinguishable from $E$. coli colonies by their macro- 
scopic and microscopic characteristics and their failure to grow on MacConkey-MUG.

\section{Discussion}

FBA supplemented with L-phenylalanine and Ltryptophan proved suitable for the rapid and easy detection of five biochemical characteristics of gramnegative bacteria, that are useful for their identification: lactose fermentation, $\beta$-glucuronidase (MUG hydrolysis), phenylalanine deaminase, indole production and cytochrome oxidase. The reaction patterns obtained with the modified isolation medium were highly specific for recognising $E$. coli, $P$. mirabilis and $P$ s. aeruginosa isolates, which account for $c .85 \%$ of all gram-negative isolates from UTI. The remaining gram-negative isolates could be identified with an approximation that was sufficient for clinical purposes. The same medium is suitable for isolating grampositive micro-organisms, that are easily distinguish-

\section{References}

1. Le Minor L, Ben Hamida F. Avantages de la recherche de la $\beta$ galactosidase sur celle de la fermentation du lactose en milieu complexe dans le diagnostic bactériologique, en particulier des Enterobacteriaceae. Ann Inst Pasteur 1962; 102: $267-277$

2. Brisou B, Richard C, Lenriot $A$. Intérêt taxonomique de la recherche de la $\beta$-xilosidase chez les Enterobacteriaceae. Ann Inst Pasteur 1972; 123: 341-347.

3. Kilian M, Bülow P. Rapid diagnosis of Enterobacteriaceae: I. Detection of bacterial glycosidases. Acta Pathol Microbiol Scand (Sect B) 1976; 84: 245-251.

4. Giammanco G, Buissière J, Toucas M, Brault C, Le Minor L. Intérêt taxonomique de la recherche de la $\gamma$-glutamyltransférase chez les Enterobacteriaceae. Ann Microbiol (Inst Pasteur) 1980; 131 A: 181-187.

5. Giammanco G, Falci A. The detection of Salmonella and Shigella with the aid of a new medium for the simultaneous assay of $\beta$-galactosidase phenylalanine deaminase and motility. Ann Inst Pasteur 1971; 120: 525-530.

6. Kilian M, Bülow P. Rapid identification of Enterobacteriaceae : II. Use of a $\beta$-glucuronidase detecting agar medium (PGVA able from gram-negative bacteria by their colonial morphology and microscopic characteristics. The majority of Staph. haemolyticus isolates can be identified on the isolation medium by their $\beta$-glucuronidase activity. ${ }^{12}$ Enterococci can be distinguished by their lack of catalase reactivity. The selective MacConkey Agar MUG supplemented with L-phenylalanine also proved suitable for detecting the same biochemical characteristics, except for indole production. In consequence, the differentiation of $P$. mirabilis from other Proteus-Providencia species is not possible on this medium. Like the non-selective medium, the modified MacConkey Agar MUG was highly efficient at making a presumptive identification of $E$. coli.

The amino-acid supplementation of the two media is easy to perform and not very expensive. Moreover, use of the two modified media renders unnecessary many of the biochemical tests used to identify urinary isolates. In this way the bacteriological investigations for the aetiological diagnosis of UTI for both clinical and epidemiological purposes can be made quickly and economically.

agar) for the identification of $E$. coli in primary cultures of urine samples. Acta Pathol Microbiol Scand (Sect B) 1979; 87: $271-276$.

7. Trepeta RW, Edberg SC. Methylumbelliferyl- $\beta$-D-glucuronidebased medium for rapid isolation and identification of Escherichia coli. J Clin Microbiol 1984: 19: 172-174.

8. Thaller MC, Berlutti F, Dainelli B, Pezzi R. New plate medium for screening and presumptive identification of gramnegative urinary tract pathogens. $J$ Clin Microbiol 1988 ; 26: 791-793.

9. Döller PC, Heizmann WR, Werner H. Rapid identification of Escherichia coli in monomicrobial urine specimens by a fluorogenic assay. J Microbiol Methods 1990; 12: 51-55.

10. Brenner DJ. Enterobacteriaceae. In: Krieg NR, Holt JG (eds) Bergey's Manual of systematic bacteriology, vol 1. Baltimore, USA, Williams and Wilkins. 1984.

11. Palleroni NJ. Pseudomonas. In: Krieg NR, Holt JG (eds) Bergey's Manual of systematic bacteriology, vol 1 . Baltimore, USA, Williams and Wilkins. 1984; 165.

12. Kloos WE, Wolfshohl JF. Identification of Staphylococcus species with the API STAPH-IDENT system. J Clin Microbiol 1982; 16: 509-516. 